\title{
Pulmonary Thromboses in Pediatric Acute Respiratory Distress Syndrome
}

\author{
Magalie Caudron, Tanya Holt, Geoff DE Cuvelier, Jeffrey Dmytrowich, and Gregory Hansen
}

\author{
Introduction \\ Epidemiology of Pediatric ARDS and Pulmonary Emboli \\ In Situ Pulmonary Artery Thrombosis \\ Pathophysiologic Consequences of Pulmonary Thromboses \\ Proposed Diagnostic Pathway for Pulmonary Thromboses in ARDS \\ Pulmonary Thromboses Treatment \\ Mechanical Ventilation Considerations With Pulmonary Thromboses \\ Outcomes \\ Summary
}

\begin{abstract}
Pediatric ARDS continues to be a management challenge in the ICU with prolonged hospitalizations and high mortality. Thromboembolic pulmonary embolism and in situ pulmonary artery thrombosis might represent underappreciated thrombotic processes for a subset of these patients. Although well described in the adult literature, descriptions of pulmonary thromboses with pediatric ARDS are limited to case reports. However, many risk factors for pulmonary thromboses are present in children with ARDS (eg, coagulopathy, endothelial injury, central venous catheters, concomitant inflammatory diseases), suggesting a much higher incidence is plausible. Based on an interpretation of animal, pediatric, and adult data, we propose a diagnostic algorithm to facilitate a timely and accurate diagnosis. Observing an alveolar dead space fraction $\geq \mathbf{0 . 2 5}$, or either a $\mathbf{5 0 \%}$ increase in physiologic dead space/tidal volume or a central venous saturation $\leq 60 \%$ over $24 \mathrm{~h}$, triggers the algorithm. Together with targeted heparin treatment and right ventricular afterload reduction, clinical outcomes might improve if this particular patient subgroup can be identified early. While anticoagulation is recommended in adults with confirmed pulmonary embolism and low early mortality risk, data for children are limited. Key words: acute respiratory distress syndrome; pediatrics; pulmonary embolism; thrombosis. [Respir Care 2019;64(2):209-216. (C 2019 Daedalus Enterprises]
\end{abstract}

\section{Introduction}

In 1967, Ashbaugh and colleagues first documented ARDS through a case series of 12 adult patients with acute

Dr Caudron is affiliated with the Division of Pediatric Critical Care, University of British Columbia, Vancouver, British Columbia, Canada. Dr Holt, Dr Hansen, and Mr Dmytrowich are affiliated with the Division of Pediatric Critical Care, Department of Pediatrics, College of Medicine, University of Saskatchewan, Saskatoon, Saskatchewan, Canada. Dr Cuvelier tachypnea, hypoxemia, and loss of pulmonary compliance. ${ }^{1}$ Although they noted clinical and pathologic similarities to respiratory distress in infants, pediatric-specific definitions of ARDS were only recently proposed. ${ }^{2}$ Despite this limitation, our understanding of pediatric ARDS has evolved

\footnotetext{
is affiliated with Pediatric Hematology-Oncology-BMT, CancerCare Manitoba, Winnipeg, Manitoba, Canada.
}

The authors have disclosed no conflicts of interest. 


\section{Pulmonary Thromboses in Pediatric ARDS}

over the past 50 years and has increased our respect for this challenging condition.

Recommendations for lung-protective mechanical ventilation strategies, ${ }^{3}$ monitoring, ${ }^{4}$ and non-pulmonary support $^{5}$ are well established for pediatric ARDS; however, it continues to be associated with high mortality and significant long-term morbidity. ${ }^{6}$ Given the broad phenotype and heterogeneity of lung disease in pediatric ARDS, other factors should be considered to improve outcomes. Pulmonary thromboses secondary to thromboembolic pulmonary emboli (PE) or in situ pulmonary artery thrombosis are noted pathophysiologic sequelae of ARDS, and they are associated with pulmonary vascular dysfunction ${ }^{7-9}$ and higher mortality. ${ }^{10}$ Thromboembolic PE describes classic thromboembolic events from distant non-pulmonary sources, while in situ pulmonary artery thrombosis develops from local pulmonary pathophysiological processes. ${ }^{11}$ A paucity of literature reports these thrombotic patterns in children.

After reporting the case of an 18-month-old boy with ARDS and pulmonary thromboses, ${ }^{12}$ we sought to review the literature and propose a diagnostic strategy for recognition and treatment of early thromboses. For clarity, thrombi are defined as intravascular blood clots versus thromboses as the presence or formation of thrombi.

\section{Epidemiology of Pediatric ARDS and Pulmonary Emboli}

The determination of epidemiologic data for pediatric ARDS is limited in part by the paucity of large studies, the heterogeneity of definitions in the literature, and its broad etiology and clinical phenotype. Hence, wide ranges in incidence from 2 to 12.8 per 100,000 children are reported for developed countries. ${ }^{13-17}$ Pediatric ARDS also accounts for $1.4-3.2 \%$ of pediatric ICU admissions ${ }^{13-17}$ and approximately $8 \%$ of mechanically ventilated children. ${ }^{16,18}$ The burden of illness might be higher in developing countries, ${ }^{19}$ reflecting differences in infectious etiologies, prehospital infrastructure, availability of life-sustaining technologies, and baseline health and nutritional status.

$\mathrm{PE}$ in children is a rare condition associated with significant morbidity and mortality. North American data from all-comers suggests an annual incidence of 5.7 per 10,000 admissions $^{20}$ and annual diagnosis rates of $0.9-4.6$ per 100,000 children. ${ }^{20,21}$ However, the diagnosis of thromboembolic PE can be challenging due to subtle and nonspecific clinical presentation as well as a lack of reliable

Correspondence: Gregory Hansen, Pediatric Intensive Care Unit, 103 Hospital Drive, Saskatoon, SK, Canada S7N 0W8. E-mail: gregory.hansen@usask.ca.

DOI: $10.4187 /$ respcare.06106 screening protocols and investigations. Accordingly, pediatric autopsy studies suggest a much higher incidence ranging of $0.05-4.2 \%$, with only half of the patients demonstrating clinical signs and symptoms of thromboembolic PE. 22,23

The pediatric ARDS patient might be particularly vulnerable to thromboembolic PE. Multiple major risk factors (eg, systemic infection, ICU admission, central venous catheter, mechanical ventilation, prolonged hospitalization, trauma, cardiopulmonary bypass, inflammatory disease, and malignancy $)^{24}$ are often present during a typical pediatric ICU admission for ARDS. This is supported by postmortem evaluations of adults that indicate thromboemboli in $95 \%$ of subjects with ARDS. ${ }^{25}$ However, such supportive data are not available for pediatric patients.

\section{In Situ Pulmonary Artery Thrombosis}

The differentiation between thromboembolic PE and in situ pulmonary artery thrombosis is not clearly elucidated in the pediatric ARDS literature. In adult ARDS, in situ pulmonary artery thrombosis is characterized as microand macrothrombi, with balloon-occlusion angiography studies demonstrating arterial filling detects in $42-48 \%$ of patients. ${ }^{10,26,27}$ Postmortem adult studies show even greater involvement, with $86 \%$ of patients demonstrating macrothrombi. ${ }^{25}$

The relationship between in situ pulmonary artery thrombosis and pediatric ARDS emerges from burgeoning pathophysiologic evidence of endothelial damage and dysfunction in lung vasculature, with resultant pulmonary intravascular thrombi. Adult studies suggest that the underlying condition (eg, infection, trauma, malignancy) promotes the pro-inflammatory milieu that results in ARDS, but significant endothelial cell injury occurs concurrently with subendothelial collagen and tissue-factor exposure. Activation of factor VII leading to initial thrombin generation then promotes a more general activation of the coagulation cascade and platelets. ${ }^{28-30}$ Other potential contributing factors include hypoxic vasoconstriction and extrinsic vascular compression. ${ }^{28-30}$ Despite more recent advances, pediatric data remain sparse, and the pathophysiologic context of the immature cardio-respiratory, hematologic, and hemostatic systems is largely unknown.

Procoagulant and antifibrinolytic changes are reported in adult patients with ARDS. Bronchoalveolar fluid and plasma samples demonstrate elevated tissue factor, increased factors VII, VIII, and X activity, ${ }^{31,32}$ elevated plasminogen activator inhibitor-1,33,34 elevated thrombomodulin, ${ }^{33}$ and decreased protein C. ${ }^{34-35}$ Furthermore, these changes are associated with increased mortality and morbidity. ${ }^{33-36}$ Similar associations are confirmed in the pediatric population. Sapru et $\mathrm{al}^{37}$ demonstrated a dose-response relationship between the levels of plasminogen activator 
inhibitor 1 and mortality as well as ventilator-free days in children with ARDS. Decreased antithrombin III levels are also associated with mortality in pediatric ARDS. ${ }^{38}$ Biomarkers of endothelial injury such as thrombomodulin, ${ }^{39}$ von Willebrand factor, ${ }^{40}$ angiopoietin 2 , and soluble receptor for advance glycation end products ${ }^{41}$ are also associated with increased mortality and decreased ventilatorfree days in pediatric ARDS. These biomarkers suggest that coagulopathy and endothelial injury are important pathophysiologic features, and they support a biologic plausibility for in situ pulmonary artery thrombosis in pediatric ARDS. Furthermore, coagulopathy biomarkers and microvascular thromboses are also established in pediatric pneumonia, ${ }^{42}$ sepsis, ${ }^{43}$ and multiorgan failure, ${ }^{44}$ which are conditions that can overlap with an ARDS diagnosis.

\section{Pathophysiologic Consequences of Pulmonary Thromboses}

The pathophysiologic consequences of pulmonary thromboses are increased alveolar dead space, a resultant $\dot{\mathrm{V} / \mathrm{Q}}$ (ventilation/perfusion) mismatch, and increased pulmonary vascular resistance (PVR). However, these changes must be interpreted within the context of expected $\dot{V} / \dot{Q}$ mismatches from ARDS, which are caused by changes to pulmonary microcirculation, pulmonary vascular dysfunction, and potentially alveolar hyperinflation. Subtleties cannot be appreciated without the routine use of arterial blood gas monitoring and capnography as well as interpretation of newer and more sophisticated mechanical ventilator waveform analysis and dead space quantification. ${ }^{4}$

Sudden or significant changes to alveolar dead space can represent a sentinel warning sign for large thromboembolic PE. Volumetric capnography can measure acute changes in breath-to-breath alveolar dead space and commonly includes the interpretation of ventilation dead space with tidal volume $\left(\mathrm{V}_{\mathrm{D}} / \mathrm{V}_{\mathrm{T}}\right)$ and mixed expired air. ${ }^{45,46} \mathrm{How}-$ ever, the literature also reports calculated dead space values (ie, primarily end-tidal alveolar dead space fraction: $\left[\mathrm{P}_{\mathrm{aCO}_{2}}-\mathrm{P}_{\mathrm{ETCO}_{2}}\right] / \mathrm{P}_{\mathrm{aCO}}$, or AVDSf), making comparisons between studies challenging. With severe $\mathrm{PE}, \mathrm{V}_{\mathrm{D}} / \mathrm{V}_{\mathrm{T}}$ rapidly increases by nearly $50 \%$ in adults ${ }^{47}$ and ADVSf increases by $100 \%$ in porcine models. ${ }^{48}$ Following pulmonary thromboendarterectomy in intubated adults, $\mathrm{V}_{\mathrm{D}} / \mathrm{V}_{\mathrm{T}}$ decreases by nearly $50 \%$ the following day. ${ }^{49}$

Detecting in situ pulmonary artery thrombosis remains problematic because its gradual yet progressive trajectory might correlate temporally with evolving pediatric ARDS. Increased alveolar dead space has been demonstrated in adult $^{50,51}$ and pediatric ${ }^{52-54}$ subjects with ARDS. Its association with increased mortality suggests the possibility of underlying pulmonary microvascular alterations. ${ }^{52,54} \mathrm{In}$ adults, treatment with activated protein $\mathrm{C}$ decreases dead space, suggesting that the increased dead space might re- flect microvascular obstruction. ${ }^{55}$ An AVDSf $\geq 0.25$ at pediatric ARDS onset is associated with a significantly higher mortality rate. ${ }^{54} \mathrm{~A}$ high AVSDf that has not improved within $24 \mathrm{~h}$ from its baseline measurement is also a poor prognostic indicator. ${ }^{53}$

Bedside screening for the presence or magnitude of right heart strain secondary to increased PVR is non-specific and non-sensitive. Adult data suggest that a change in mixed venous oxygen saturations $\left(\mathrm{S}_{\bar{v}_{\mathrm{O}}}\right)$ following severe $\mathrm{PE}$ is the most sensitive predictor of PE compared to all other standard hemodynamic variables (including systolic arterial pressure, cardiac index, pulmonary artery pressure, urine output, and lactate). ${ }^{56}$ In pediatric patients, central $\mathrm{S}_{\overline{\mathrm{v}}_{2}}$ are typically obtained instead, ${ }^{57}$ with thresholds $\geq 70 \%$ associated with improved outcomes in conditions with abnormal hemodynamics such as septic shock. ${ }^{58}$

\section{Proposed Diagnostic Pathway for Pulmonary Thromboses in ARDS}

The diagnosis of pediatric ARDS is made by the application of clinical criteria utilizing consensus definitions. Earlier observations by Ashbaugh et $\mathrm{al}^{1}$ gradually led to the Berlin definition for ARDS in 2012,59 which has since been validated in both adults and children. More recently, the Pediatric Acute Lung Injury Consensus Conference also developed pediatric specific definitions. ${ }^{2}$ With no recommendations regarding the diagnosis of pulmonary thromboses and pediatric ARDS, ${ }^{60}$ we propose an algorithm based on the best available evidence (Fig. 1).

While clinically important pulmonary thromboses are thought to be rare in pediatric ARDS, the evidence suggests that the concomitant lung disease either conceals or results in this under-diagnosis. Unfortunately, clinical signs and symptoms of pulmonary thromboses, as well as the utilization of D-dimer or probability scoring systems, are low-yield when investigating such diagnoses in children. ${ }^{61}$ In the event that a pulmonary thromboses diagnosis is made, a significant lag (1-7 d) from symptom onset often exists. ${ }^{62}$ Hence, actual incidence cannot be appreciated unless the clinician begins with a high index of suspicion for all pediatric ARDS patients.

Diagnostic variables for alveolar dead space and elevated PVR have not been validated in pediatric patients with ARDS and pulmonary thromboses. Nevertheless, we propose the following three thresholds to initiate our diagnostic algorithm based on the summative data presented earlier: (i) an AVDSf $\geq 0.25$; (ii) a $50 \%$ increase of $V_{D} / V_{T}$ within $24 \mathrm{~h}$; or (iii) a central $\mathrm{S}_{\overline{\mathrm{v}}_{2}} \leq 60 \%$ within $24 \mathrm{~h}$.

The proposed changes to dead space and central $\mathrm{S}_{\overline{\mathrm{v}} \mathrm{O}_{2}}$ should prompt subsequent investigations to rule out causes other than pulmonary thromboses. Although chest radiography has a low sensitivity and specificity for pulmonary thromboses, it might be helpful to exclude clinical mim- 


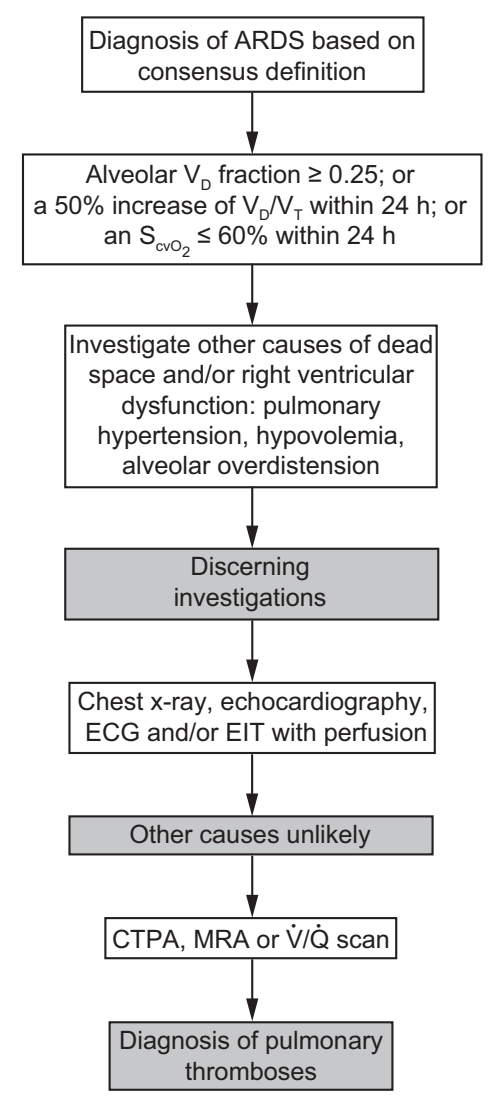

Fig. 1. Proposed diagnostic pathway for pulmonary thromboses with pediatric $A R D S . V_{D} / V_{T}=$ dead space/tidal volume; $E C G=$ electrocardiogram; EIT = electrical impedance tomography; CTPA = CT pulmonary angiogram; MRA = magnetic resonance angiography.

ickers. Electrocardiograms should be obtained; however, evidence of the classic S1Q3T3 finding is only reported in $12 \%$ of acute thromboembolic PE in children, and other abnormalities such as right axis deviation and right bundle branch block are not very reliable. ${ }^{63,64}$ Bedside Doppler echocardiography is not systematically used in pediatric ARDS, but it might be useful in evaluating ARDS severity with the suspected continuum of alterations in pulmonary circulation and right ventricular function. ${ }^{65}$ In adults, a recent meta-analysis suggests that transthoracic echocardiography consistently demonstrates a high specificity and low sensitivity in the diagnosis of PE, ${ }^{66}$ but its generalizability to children is uncertain. ${ }^{63,67}$ Finally, improvements in electrical impedance tomography might be the future for evaluating bedside pulmonary perfusion for critically ill patients. ${ }^{68}$ Its advantages include safety, portability, realtime assessment without radiation, and burgeoning research detecting small changes in ventilation and perfusion impedance induced by large thromboembolic PE. ${ }^{69-72}$ However, clinical validation is lacking, and further effort is required to improve the detection of small perfusion-impedance signal changes. ${ }^{68}$ Once optimized, electrical im- pedance tomography has the potential to detect smaller pulmonary artery filling defects that could be secondary to smaller pulmonary thrombi.

Diagnostic imaging for thromboembolic PE has predominantly included computed tomography with pulmonary angiography and $\dot{V} / \mathbf{Q}$ scans. Concordance studies between these modalities have not been conducted in children, and their respective sensitivity and specificity are difficult to determine because many thromboembolic PE are diagnosed postmortem. ${ }^{11} \dot{\mathrm{V}} / \mathrm{Q}$ scanning presents major logistical challenges to the ventilated child with the requirement of aerosol inhalation, often limiting the investigation to perfusion studies only. Pulmonary angiography is another alternative, but it is invasive, is time-consuming, introduces potential complications, and is not always available. ${ }^{73}$ For in situ pulmonary artery thrombosis, optimal imaging modalities are difficult to discern because a strict differentiation from thromboembolic PE has not been made consistently. ${ }^{11}$ Newer modalities such as pulmonary magnetic resonance angiography are promising, but they might present several practical challenges in critically ill children due to long examination times and difficulties with patient monitoring.

\section{Pulmonary Thromboses Treatment}

Despite the identified pathophysiologic risk of thromboses with pediatric ARDS, the current treatment strategies with these patients target ventilator adjustments with disease evolution. ${ }^{3}$ It is unclear how often respiratory deteriorations are secondary to pulmonary thromboses, as is whether treatment with anticoagulation should be initiated with only a high index of clinical suspicion. A recent meta-analysis of randomized, controlled trials in adults suggests adjuvant treatment with low-molecular-weight heparin was associated with reducing 7-d and 28-d mortality and improved oxygenation among subjects with acute lung injury/ARDS. ${ }^{74}$ Promising new anticoagulation therapies in adults have not been successful in large ARDS clinical trials, but smaller and selective patient subgroups who might have benefitted were never delineated a priori. ${ }^{75}$

Initial anticoagulation with unfractionated heparin or low-molecular-weight heparin should be considered in pediatric pulmonary thromboses. ${ }^{11,76}$ Unfractionated heparin offers the advantage of rapid reversibility by discontinuing the infusion or by administering protamine in the situation of significant bleeding. Disadvantages include the need for a dedicated line for infusion and the requirement for frequent monitoring, ideally with both an activated partial thromboplastin time and anti-Xa level for correlation. Unfractionated heparin also strongly binds plasma proteins, including inflammatory cytokines (invariably present in pediatric ARDS), which can result in potential undershooting of the activated partial thromboplastin time range de- 
spite apparently normal starting doses. Finally, unfractionated heparin (relative to low-molecular-weight heparin) places the patient at higher risk for heparin-induced thrombocytopenia, a condition that can paradoxically worsen the thrombotic event.

By comparison, low-molecular-weight heparin offers the advantage of a subcutaneous injection 1-2 times per day with generally less frequent required monitoring of anti-Xa levels. ${ }^{77}$ Furthermore, low-molecular-weight heparin does not affect the activated partial thromboplastin time, so monitoring of thromboplastin times is not required. A major disadvantage to low-molecular-weight heparin is the suboptimal reversibility relative to unfractionated heparin in case of bleeding. Systemic thrombolytic therapy is reserved for thrombi that create life-threatening hemodynamic instability. Local installation of thrombolytic therapy through the pulmonary artery via catheterization is another potential alternative, although its efficacy in children is unknown.

The risk of major hemorrhage with anticoagulation and thrombolysis is reported in $21.8 \%$ and up to $40 \%$ of children, respectively: ${ }^{78}$ therefore, initiation of empiric anticoagulation in suspected but not proven pulmonary thrombosis is debatable. Furthermore, monitoring frequency and target ranges for anticoagulation therapy have not been evaluated in large prospective trials. However, if anticoagulation is initiated, the current recommendations are to target anti-Xa levels of $0.35-0.7$ units $/ \mathrm{mL}$ and $0.5-$ $1.0 \mathrm{units} / \mathrm{mL}$ for unfractionated heparin and low-molecular-weight heparin, respectively. ${ }^{77}$ Significant variation in duration of anticoagulation therapy is noted ${ }^{11}$ and should be directed by thrombosis consultants.

\section{Mechanical Ventilation Considerations With Pulmonary Thromboses}

Optimal ventilatory support for children with pulmonary thromboses has not been clearly described. Although noninvasive positive-pressure ventilation might be considered with milder pediatric ARDS, ${ }^{79}$ pulmonary thromboses usually heralds worsening gas exchange and will typically require intubation. For these patients, ARDS guidelines suggest open lung strategies with moderately elevated PEEP values and small $\mathrm{V}_{\mathrm{T}}$ for conventional ventilation modes. ${ }^{3}$ Recommended alternatives for poor pulmonary compliance and hypoxemic respiratory failure are prone ventilation and high-frequency oscillation ventilation. ${ }^{3}$ Specific caveats for pulmonary thromboses within the guidelines have not been made.

Additional principles to address for optimizing gas exchange impeded by thromboses are reducing right ventricular afterload and promoting pulmonary circulation. Echocardiographic data from $<72 \mathrm{~h}$ after acute $\mathrm{PE}$ demonstrate right ventricular dysfunction in $25 \%$ of pediatric cases. ${ }^{63}$
Therefore, PVR can be mitigated by avoiding atelectatic and over-distended alveoli, but finding the appropriate balance can be challenging. Both inhaled nitric oxide ${ }^{80}$ and milrinone ${ }^{81}$ are reported for management of acute pulmonary thromboses in adults, and these could be considered for children. In addition to pulmonary vasodilation, milrinone exerts both positive inotropic and lusitropic effects to support the right ventricle.

\section{Outcomes}

The paucity of outcome data on pediatric pulmonary thromboses and ARDS is likely related to present limitations related to quantifying thromboses and differentiating procoagulant processes with nonthrombotic vascular dysfunction. If pulmonary thromboses are associated with raised PVR, poorer outcomes could be related to either right ventricular failure or exacerbation of lung injury. ${ }^{7}$ Although right ventricular dysfunction has been independently associated with increased morbidity and mortality in adults with pulmonary vascular dysfunction and ARDS, ${ }^{8,9}$ and elevated PVR might indicate disease severity and progression, ${ }^{7}$ causal conclusions concerning thrombotic outcomes cannot be made.

As a surrogate, separate pediatric outcome data from ARDS and thromboembolic PE could be considered. Mortality from pediatric ARDS ranges from $15 \%$ to $50 \%$, reflecting differing etiologies, patient comorbidities, ventilatory strategies, pediatric ICU care, and time of study. ${ }^{6}$ Some mortality risk factors might exacerbate the procoagulant, antifibrinolytic phenotype of pediatric ARDS (eg, disseminated intravascular coagulation, ${ }^{82}$ non-pulmonary sepsis, ${ }^{13}$ multiorgan failure ${ }^{83}$ ) and pulmonary vascular dysfunction (eg, immunosuppression, ${ }^{13,84}$ high $\mathrm{V}_{\mathrm{T}}{ }^{85}$ ), or they may encourage thromboembolic events (eg, hematologic malignancies ${ }^{85,86}$ ). Children who survive pediatric ARDS require hospital admissions for $>20 \mathrm{~d}^{15}$ and can develop chronic obstructive and restrictive pulmonary disease. ${ }^{6} \mathrm{~A}$ recent pediatric review estimated mortality at $26 \%$ ( $n=15$ studies) and $<20 \%$ ( $n=9$ case series $)$ from thromboembolic PE and in situ pulmonary artery thrombosis, respectively. ${ }^{11}$ While pediatric ARDS might not have evolved in many of these cases (ie, thrombi secondary to congenital heart disease, pulmonary artery anomalies), the coupling of thromboses with pediatric ARDS likely represents a more severe presentation with poorer outcomes.

In our case report, ${ }^{12}$ inhaled nitric oxide did not improve oxygenation, but a milrinone infusion did. The patient was treated with a heparin infusion, and within $72 \mathrm{~h}$ a significant improvement in his dead space ventilation was noted. His ventilator support was gradually weaned, and he was successfully extubated on day 18 of his pediatric ICU admission. He continues to be followed by both respirology and cardiology specialists, and long-term sequelae have yet to be documented. 


\section{Pulmonary Thromboses in Pediatric ARDS}

\section{Summary}

The most recent major recommendation by the Subcommittee on Pediatric and Neonatal Thrombosis and Hemostasis outlines the need to improve awareness and education for the prompt investigation and diagnosis of pulmonary thromboses in children. ${ }^{87}$ Thromboembolic PE and in situ pulmonary artery thromboses are likely underrecognized in pediatric ARDS cases, and their current role in patient outcomes is unknown. Awareness of patients at risk for pulmonary thrombosis within the heterogeneous context of pediatric ARDS should be coupled with diagnostic pathways that might include changes in the ventilatory dead space fraction and emerging bedside technologies. Together, earlier diagnosis with timely and targeted treatment might attenuate right heart strain and pulmonary artery dysfunction, and it may improve patient morbidity and mortality. Whether our proposed diagnostic pathway will increase thrombi detection is unknown, and we will evaluate its efficacy by incorporating electrical impedance tomography once perfusion software is available.

\section{REFERENCES}

1. Ashbaugh DG, Begelow DB, Petty TL, Levine BE. Acute respiratory distress in adults. Lancet 1967;2(7511):319-323.

2. Khemani R, Smith LS, Zimmerman JJ, Erickson S, on behalf of the Pediatric Acute Lung Injury Consensus Conference Group. Pediatric acute respiratory distress syndrome: definition, incidence, and epidemiology: proceedings from the Pediatric Acute Lung Injury Consensus Conference. Pediatr Crit Care Med 2015;16(Suppl 1):S2-S40.

3. Rimensberger PC, Cheifetz IM, on behalf of the Pediatric Acute Lung Injury Consensus Conference Group. Ventilatory support in children with pediatric acute respiratory distress syndrome: proceedings from the Pediatric Acute Lung Injury Consensus Conference. Pediatr Crit Care Med 2015;16(Suppl 1):S51-S60.

4. Emeriaud G, Newth CJL, on behalf of the Pediatric Acute Lung Injury Consensus Conference Group. Monitoring of children with pediatric acute respiratory distress syndrome: proceedings from the Pediatric Acute Lung Injury Consensus Conference. Pediatr Crit Care Med 2015;6(Suppl 1):S86-S101.

5. Valentine SL, Nadkarni VM, Curely MAQ, on behalf of the Pediatric Acute Lung Injury Consensus Conference Group. Nonpulmonary treatments for pediatric acute respiratory distress syndrome: proceedings from the Pediatric Acute Lung Injury Consensus Conference. Pediatr Crit Care Med 2015;16(Suppl 1):S73-S85.

6. Quasney MW, López-Fernández YM, Santschi M, Watson RS, on behalf of the Pediatric Acute Lung Injury Consensus Conference Group. The outcomes of children with pediatric acute respiratory distress syndrome: proceedings from the Pediatric Acute Lung Injury Consensus Conference. Pediatr Crit Care Med 2015;16(Suppl 1): S118-S131.

7. Ryan D, Frohlich S, McLoughlin P. Pulmonary vascular dysfunction in ARDS. Ann Intensive Care 2014;4:28.

8. Bull TM, Clark B, McFann K, Moss M, on behalf of the National Institutes of Health/National Heart, Lung, and Blood Institute ARDS Network. Pulmonary vascular dysfunction is associated with poor outcomes in patients with acute lung injury. Am J Respir Crit Care Med 2010;182(9):1123-1128.
9. Boissier F, Katsahian S, Razazi K, Thille AW, Roche-Campo F, Leon R, et al. Prevalence and prognosis of cor pulmonale during protection ventilation for acute respiratory distress syndrome. Int Care Med 2013;39(10):1725-1733.

10. Greene R, Zapol WM, Snider MT, Reid L, Snow R, O'Connell RS, Novelline RA. Early bedside detection of pulmonary vascular occlusion during acute respiratory failure. Am Rev Respir Dis 1981; 124(5):593-601.

11. Rajpurkar M, Biss T, Amankwah E, Martinez D, Williams, van Ommen $\mathrm{CH}$, Goldenberg NA. Pulmonary embolism and in situ pulmonary artery thrombosis in paediatrics: a systematic review. Thromb Haemost 2017;117(6):1199-1207.

12. Caudron M, Holt T. Pulmonary embolism in a child with ARDS secondary to foreign body aspiration. Crit Care Med 2016;44(12): 549.

13. Erikson S, Schilber A, Numa A, Nuthall G, Yung M, Pascoe E, Wilkins B, on behalf of the Paediatric Study Group and Australian and New Zealand Intensive Care Society. Acute lung injury in pediatric intensive care in Australia and New Zealand: a prospective, multicenter, observational study. Pediatr Crit Care Med 2007;8(4): 317-323.

14. López-Fernández Y, Azagra Am, de la Oliva P, Modesto V, Sánchez JI, Parrila J, et al., on behalf of the Pediatric Acute Lung Injury Epidemiology and Natural History (PED-ALIEN) Network. Pediatric acute lung injury epidemiology and natural history study: incidence and outcome of the acute respiratory distress syndrome in children. Crit Care Med 2012;40(12):3238-3245.

15. Zimmerman JJ, Aktar SR, Caldwell E, Rubenfeld. Incidence and outcomes of pediatric acute lung injury. Pediatrics 2009;124(1): 87-95.

16. Kneyber MC, Brouwers AG, Caris JA, Chedami B, Plötz FB. Acute respiratory distress syndrome: is it underrecognized in the pediatric intensive care unit? Intensive Care Med 2008;34(4):751-754.

17. Bindl L, Dresbach K, Lentze MJ. Incidence of acute respiratory distress syndrome in German children and adolescents: a populationbased study. Crit Care Med 2005;33(1):209-312.

18. Dahlem P, van Aalderen WM, Hamaker ME, Dijkgraaf MG, Bos AP. Incidence and short-term outcome of acute lung injury in mechanically ventilated children. Eur Respir J 2003;22(8):980-985.

19. Barreira ER, Munoz GOC, Cavalheiro PA, Suzuki AS, Degaspare $\mathrm{NV}$, Shieh HH, et al., on behalf of the Brazilian Pediatric Acute Respiratory Distress Syndrome Study Group. Epidemiology and outcomes of acute respiratory distress syndrome in children according to the Berlin Definition: a multicenter prospective study. Crit Care Med 2015;43(5):947-953.

20. Biss TT, Brandão LR, Kahr WH, Chan AK, Williams S. Clinical features and outcome of pulmonary embolism in children. Br J Haematol 2008;142(5):808-818

21. Stein PD, Kayali F, Olson RE. Incidence of venous thromboembolism in infants and children: data from the National Hospital Discharge Survey. J Pediatr 2004;145(4):563-565.

22. Buck JR, Connors RH, Coon WW, Weintraub WH, Wesley JR, Coran AG. Pulmonary embolism in children. J Pediatr Surg 1981; 16(3):385-391.

23. Byard RW, Cutz E. Sudden and unexpected death in infancy and childhood due to pulmonary thromboembolism: an autopsy study. Arch Pathol Lab Med 1990;114(2):142-144.

24. Mahajerin A, Branchford BR, Amankwah EK, Raffini L, Chalmers E, van Ommen $\mathrm{CH}$, Goldenberg NA. Hospital-associated venous thromboembolism in pediatrics: a systematic review and meta-analysis of risk factors and risk-assessment models. Haematologica 2015; 100(8):1045-1050. 


\section{Pulmonary Thromboses in Pediatric ARDS}

25. Tomashefski JF Jr, Davies P, Boggis C, Greene R, Zapol WM, Reid LM. The pulmonary vascular lesions of the adult respiratory distress syndrome. Am J Pathol 1983;112(1):112-126.

26. Greene R. Pulmonary vascular obstruction in the adult respiratory distress syndrome. J Thorac Imaging 1986;1(3):31-38.

27. Vesconi S, Rossi GP, Pesenti A, Fumagalli R, Gattinoni L. Pulmonary microthrombosis in severe adult respiratory distress syndrome. Crit Care Med 1988;16(2):111-113.

28. Tomashefski JF Jr. Pulmonary pathology of acute respiratory distress syndrome. Clin Chest Med 2000;21(3):435-466.

29. Peñuelas O, Aramburu JA, Frutos-Vivar F, Esteban A. Pathology of acute lung injury and acute respiratory distress syndrome: a clinicalpathological correlation. Clin Chest Med 2006;27(4):571-578.

30. Levi M, Schultz M. The inflammation-coagulation axis as an important intermediate pathway in acute lung injury. Crit Care 2008; 12(2): 144.

31. Idell S, James KK, Levin EG, Schwartz BS, Manchanda N, Maunder $\mathrm{RJ}$, et al. Local abnormalities in coagulation and fibrinolytic pathways predispose of alveolar fibrin deposition in the adult respiratory distress syndrome. J Clin Invest 1989;84(2):695-705.

32. Idell S, Koenig KB, Fair DS, Martin TR, McLarty J, Maunder RJ. Serial abnormalities of fibrin turnover in evolving adult respiratory distress syndrome. Am J Physiol 1991;261(4 Pt 1):L240-L248.

33. Prabhakaran P, Ware LB, White KE, Cross MT, Matthay MA, Olman MA. Elevated levels of plasminogen activator inhibitor-1 in pulmonary edema fluid are associated with mortality in acute lung injury. Am J Physiol Lung Cell Mol Physiol 2003;285(1):L20-L28.

34. Ware LB, Fang X, Matthay MA. Protein C and thrombomodulin in human acute lung injury. Am J Physiol Lung Cell Mol Physiol 2003;285(3):L514-L521.

35. Ware LB, Matthay MA, Parsons PE, Thompson BT, Januzzi JL, Eisner MD, on behalf of the National Heart, Lung and Blood Institute Acute Respiratory Distress Syndrome Clinical Trials Network. Pathogenetic and prognostic significance of altered coagulation and fibrinolysis in acute lung injury/acute respiratory distress syndrome. Crit Care Med 2007;35(8):1821-1828.

36. McClintock D, Zhuo H, Wickersham N, Matthay MA, Ware LB. Biomarkers of inflammation, coagulation and fibrinolysis predict mortality in acute lung injury. Crit Care 2008;12(2):R41.

37. Sapru A, Curley MA, Brady S, Matthay MA, Flori H. Elevated PAI-1 is associated with poor clinical outcomes in pediatric patients with acute lung injury. Intensive Care Med 2010;36(1):157-163.

38. Lee YS, Kim S, Kang EK, Park JD. Antithrombin-III as an early prognostic factor in children with acute lung injury. Korean J Pediatr 2007;50(5):443-448.

39. Orwoll BE, Spicer AC, Zinter MS, Alkhouli MF, Khemani RG, Flori HR, et al. Elevated soluble thrombomodulin is associated with organ failure and mortality in children with acute respiratory distress syndrome (ARDS): a prospective observational cohort study. Crit Care 2015; 19:435.

40. Flori HR, Ware LB, Milet M, Matthay MA. Early elevation of plasma von Willebrand factor antigen in pediatric acute lung injury is associated with an increased risk of death and prolonged mechanical ventilation. Pediatr Crit Care Med 2007;8(2):96-101.

41. Yehya N, Thomas NJ, Meyer NJ, Christie JD, Berg RA, Margulies SS. Circulating markers of endothelial and alveolar epithelial dysfunction are associated with mortality in pediatric acute respiratory distress syndrome. Intensive Care Med 2016;42(7):1137-1145.

42. Versloet LA, Marguet C, Camargos PAM. Infection of Mycoplasma pneumonia and its importance as an etiological agent in childhood community-acquired pneumonias. Braz J Infect Dis 2007;11(5):507514 .
43. Saracco P, Vitale P, Scolfaro C, Pollio B, Pagliarino M, Timeus F. The coagulopathy in sepsis: significance and implications for treatment. Pediatr Rep 2001;3(4):e30.

44. Nguyen T, Hall M, Han Y, Fiedor M, Hasset A, Lopez-Plaza I, et al. Microvascular thrombosis in pediatric multiple organ failure: is it a therapeutic target? Pediatr Crit Care Med 2001;2(3):187-196.

45. Vercheure S, Massion PB, Vershuren F, Damas P, Magder S. Volumetric capnography: lessons from the past and current clinical applications. Crit Care 2016;20(1):184.

46. Bourgoin P, Baudin F, Brossier D, Emeriaud G, Mysocki M, Jouvet P. Assessment of Bohr and Enghoff dead space equations in mechanically ventilated children. Resp Care 2017;62(4):468-474.

47. Kline JA, Kubin AK, Patel MM, Easton EJ, Seupal RA. Alveolar dead space as a predictor of severity of pulmonary embolism. Acad Emerg Med 2000;7(6):611-617.

48. Ferreira JHT, Terzi RGG, Paschoal IA, Silva WA, Moraes AC, Moreira MM. Mechanisms underlying gas exchange alterations in an experimental model of pulmonary embolism. Braz J Med Biol Res 2006;39(9):1197-1204.

49. Kitcher A, Maus T, Wagner PD, et al. Changes in dead space ventilation following pulmonary thromboendarterectomy. Am J Respir Crit Care Med 2014;189:A1874.

50. Kallet RH, Alonso JA, Pittet JF, Matthay MA. Prognostic value of the pulmonary dead-space fraction during the first 6 days of acute respiratory distress syndrome. Respir Care 2004;49(9):1008-1014.

51. Nuckton TJ, Alonso JA, Kallet RH, Daniel BM, Pittet JF, Eisner MD, Matthay MA. Pulmonary dead-space fraction as a risk factor for death in the acute respiratory distress syndrome. $\mathrm{N}$ Engl $\mathrm{J}$ Med 2002;346(17):1281-1286.

52. Ghuman AK, Newth CJ, Khemani RG. The association between the end tidal alveolar dead space fraction and mortality in pediatric acute hypoxemia respiratory failure. Pediatr Crit Care Med 2012;13(1): 11-15.

53. Bhalla AK, Belani S, Leung D, Newth CJ, Khemani RG. Higher dead space is associated with increased mortality in critically ill children. Crit Care Med 2015;43(11):2439-2445.

54. Yehya N, Bhalla AK, Thomas NJ, Khenami RG. Alveolar dead space fraction discriminates mortality in pediatric acute respiratory distress syndrome. Pediatr Crit Care Med 2016;17(2):101-109.

55. Liu KD, Levitt J, Zhuo H, Kallet RH, Brady S, Steingrub J, et al. Randomized clinical trial of activated protein $\mathrm{C}$ for the treatment of acute lung injury. Am J Respir Crit Care Med 2008;178(6):618-623.

56. Krivec B, Voag G, Podbregar M. Monitoring mixed venous oxygen saturation in patients with obstructive shock after massive pulmonary embolism. Wien Klin Wochenschr 2004;116(9-10):326-331.

57. Martin J, Shekerdemian LS. The monitoring of venous saturations of oxygen in children with congenitally malformed hearts. Cardiol Young 2009;19(1):34-39.

58. de Oliveira CF, de Oliveira DS, Gottschald AF, Moura JD, Costa GA, Ventura AC, et al. ACCM/PALS haemodynamic support guidelines for paediatric septic shock: an outcomes comparison with and without monitoring central venous oxygenation saturation. Intensive Care Med 2008;34(6):1065-1075.

59. ARDS Definition Task Force, Ranieri WM, Rubenfeld GD, Thompson BT, Ferguson ND, Caldwall E, Fan E, et al. Acute respiratory distress syndrome: the Berlin Definition. JAMA 2012;307(23):25262533.

60. Pediatric Acute Lung Injury Consensus Conference Group. Pediatric acute respiratory distress syndrome: consensus recommendations from the Pediatric Acute Lung Injury Consensus Conference. Pediatr Crit Care Med 2015;16(5):428-439.

61. Biss TT, Brandão LR, Kahr WH, Chan AK, Williams S. Clinical probability score and $\mathrm{D}$-dimer estimation lack utility in the diagnosis 


\section{Pulmonary Thromboses in Pediatric ARDS}

of childhood pulmonary embolism. J Thromb Haemost 2009;7(10): 1633-1638.

62. Rajpurkar M, Warrier I, Chitlur M, Sabo C, Frey MJ, Hollon W, Lusher J. Pulmonary embolism-experience at a single children's hospital. Thromb Res 2007;119(6):699-703.

63. Hancock HS, Wang M, Gist KM, Gibson E, Miyamoto SD, Mourani $\mathrm{PM}$, et al. Cardiac findings and long-term thromboembolic outcomes following pulmonary embolism in children: a combined retrospective-prospective inception cohort study. Cardiol Young 2013;23(3): 344-352.

64. Dijk HS, Curtin J, Lord D, Fitzgerald DA. Pulmonary embolism in children. Paediatr Respir Rev 2012;13(2):112-122.

65. Lazzeri C, Cianchi G, Bonizzoli M, Batacchi S, Peris A, Gensini GF. The potential role and limitations of echocardiography in acute respiratory distress syndrome. Ther Adv Respir Dis 2016;10(2):136148.

66. Fields JM, Davis J, Girson L, Au A, Potts J, Morgan CJ, et al. Transthoracic echocardiography for diagnosing pulmonary embolism: a systematic review and meta-analysis. J Am Soc Echocardiogr 2017;30(7):714-723.

67. Pollard AJ, Sreeram N, Wright JG, Beath SV, Booth IW, Kelly DA. ECG and echocardiographic diagnosis of pulmonary thromboembolism associated with central venous lines. Arch Dis Child 1995; 73(2): 147-150.

68. Nguyen DT, Jin C, Thiagalingam A, McEwan AL. A review on electrical impedance tomography for pulmonary perfusion imaging. Physiol Meas 2012;33(5):695-706.

69. Leathard A, Brown BH, Campbell J, Zhang F, Morice AH, Taylor D. A comparison of ventilatory and cardiac related changes in EIT images of normal human lungs and of lungs with pulmonary emboli. Physiol Meas 1994;15(Suppl 2a):A137-A146.

70. Nguyen DT, Chik W, Kosobrodov R, Barry M, Pouliopoulos J, Jin $\mathrm{C}$, et al. Pulmonary embolism detection with electrical impedance tomography. Heart Lung Circ 2013;22(Suppl 1):S192-S193.

71. Sobota V, Suchomel J. Monitoring of pulmonary embolism using electrical impedance tomography: a case study. 2013 E-Health and Bioengineering Conference (EHB) 2013:1-4.

72. Frerichs I, Amato MB, van Kaam AH, Tingay DG, Zhao Z, Grychtol $\mathrm{B}$, et al. Chest electrical impedance tomography examination, data analysis, terminology, clinical use and recommendations: consensus statement of the TRanslational EIT developmeNt stuDy group. Tho$\operatorname{rax} 2017 ; 72(1): 83-93$.

73. Riedel M. Emergency diagnosis of pulmonary embolism. Heart 2001; 85(6):607-609.

74. Li J, Yang B, Wang H, Li. Low-molecular-weight heparin treatment for acute lung injury/acute respiratory distress syndrome: a metaanalysis of randomized controlled trials. Int J Clin Exp Med 2018; 11(2):414-422.
75. Cornet AD, Oudemans-van Straaten HM, Schultz MJ, Juffermans NP, Tuinman PR. Anticoagulants for ARDS: facts and future. Neth J Crit Care 2014;18(6):3-8.

76. Brandão LR, Labarque V, Diab Yaser, Williams S, Manson DE. Pulmonary embolism in children. Semin Thromb Hemost 2011;37(7): 772-785.

77. Manogle P, Chan AKC, Goldenberg NA, Ichord RN, Journeycake $\mathrm{JM}$, Nowak-Göttl U, et al. Antithrombic therapy in neonates and children: Antithrombotic therapy and prevention of thrombosis, 9th ed. American College of Chest Physicians Evidence-Based Clinical Practice Guidelines. Chest 2012;141(2 Suppl):e737S-e801S.

78. Lilje C, Chauhan A, Turner JP, Carson TH, Velez MC, Arcement C et al. Pediatric pulmonary embolism: diagnostic and management challenges. World J Pediatr Congenit Heart Surg 2016;9(1):110-113.

79. Essouri S, Carroll C, on behalf of the Pediatric Acute Lung Injury Consensus Conference Group. Noninvasive support and ventilation for pediatric acute respiratory distress syndrome: proceedings from the Pediatric Acute Lung Injury Consensus Conference. Pediatr Crit Care Med 2015;16(Suppl 1):S102-S110.

80. Bhat T, Neuman A, Tantary M, Bhat H, Glass D, Mannino W, et al. Inhaled nitric oxide in acute pulmonary embolism: a systematic review. Rev Cardiovasc Med 2015;16(1):1-8.

81. Sonoda K, Ikeda S, Miyahara Y, Kohno S. Successful treatment of chronic pulmonary thromboembolism by long-term intermittent administration of milrinone, a phosphodiesterase-ill inhibitor. Intern Med 2002;41(11):961-966.

82. Oren H, Cingöz I, Duman M, Yilmaz S, Irken G. Disseminated intravascular coagulation in pediatric patients: clinical and laboratory prognostic factors influencing the survival. Pediatr Hematol Oncol 2005;22(8):679-688.

83. Peters MJ, Tasker RC, Kiff KM, Yates R, Hatch DJ. Acute hypoxemic respiratory failure in children: case mix and the utility of respiratory severity indices. Intensive Care Med 1998;24(7):699-705.

84. Albuali WH, Singh RN, Fraser DD, Seabrook JA, Kavanagh BP, Parshuram CS. Have changes in ventilation practice improved outcome in children with acute lung injury? Pediatr Crit Care Med 2007;8(4):324-330.

85. Ben-Abraham R, Weinbroum AA, Augerten A, Toren A, Harel R, Vardi A, et al. Acute respiratory distress syndrome in children with malignancy: can we predict outcome? J Crit Care 2001;16(2):54-58.

86. Keenan HT, Bratton SL, Martin LD, Crawford SW, Weiss NS. Outcome of children who require mechanical ventilatory support after bone marrow transplantation. Crit Care Med 2000;28(3):830-835.

87. Biss TT, Rajpurkar M, Williams S, van Ommen $\mathrm{CH}$, Chan AKC, Goldenberg NA, on behalf of the Subcommittee on Pediatric and Neonatal Thrombosis and Hemostasis. Recommendations for future research in relation to pediatric pulmonary embolism: communication from SSC of the ISTH. J Thromb Haemost 2018;16:405-418. 